\title{
Study of the Processes of Rare and Rare-Earth Metal Extraction from Ash and Slag Materials
}

\author{
Tatiana Cherkasova $^{1}$, Elizaveta Cherkasova ${ }^{1}$, Anastasia Tikhomirova $^{1}$, Andrey \\ Golovachev $^{1}$, Oleg Dormeshkin ${ }^{2}$ \\ ${ }^{1}$ T.F. Gorbachev Kuzbass State Technical University, 650000, Russian Federation \\ ${ }^{2}$ Belarusian State Technological University, Belarus
}

\begin{abstract}
The problem of disposal of ash and slag waste in Russia and in the world is very urgent. Ash dumps occupy vast areas, damaging the ecosystem. At the same time, these wastes are independent deposits of rare and rare-earth metals, which are necessary for the production of modern high-tech devices. The efficiency of flotation and chemical methods of concentration of materials in order to extract valuable components are evaluated in the paper. The composition of the initial ash and slag samples and the resulting products of their processing were analyzed using IR spectroscopic and optical emission methods.
\end{abstract}

\section{Introduction}

The problem of using tailings and ash and slag materials generated during coal burning has not been solved both in Russia and in Kuzbass as a whole. When coal is burned at a thermal power plant, two types of solid waste are generated: slag and fly ash. This waste is deposed in ash dumps, where it is stored and kept outdoors, being unused raw materials anthropogenic deposits in which valuable trace elements are concentrated.

Currently, ash and slag are mainly used to manufacture road pavement materials, as concrete additives in construction, to construct embankments. The use of these materials in other industries is limited.

Ash waste contains a large number of compounds of rare and trace elements: strontium, vanadium, gallium, germanium, zirconium. In addition, studies have shown that in the Kuzbass coal deposits there are a large number of sites containing rare-earth elements (REE), which are necessary to produce modern functional materials and are widely used in high-tech industries [1-4].

Ash and slag waste contains chemically active toxic substances that pollute soils, ground and surface water of rivers.

Usable lands are disposed of as dumps, and ash particles containing various substances are dispersed in the atmosphere due to wind erosion, increasing environmental stress, in particular, in Kuzbass.

To date, the level of disposal and use of ash and slag materials remains extremely low, because they have a heterogeneous and complex chemical composition, which complicates their processing and obtaining valuable components, not containing undesirable impurities. Moreover, the separation of compounds of rare and rare earth metals is sufficiently 
beneficial, because they can be considered as commercial reserves contained in ash and slag of Kuznetsk coal.

The development of highly selective technologies for the extraction of rare and rareearth elements from all possible sources is an urgent task both from an economic and environmental point of view.

The main method for primary treatment of ash and slag waste is processing them with such chemical reagents as mineral acids and the subsequent processing of leach solutions [5-15]. Nitric and sulfuric acids were used as a reagent for the processing of raw materials.

Adsorption bubble methods for the extraction and separation of components (foam and foamless) are more promising compared with hydrometallurgical processing of raw materials that require large expenditures of reagents and energy.

Ion flotation is just such a method. In this case, processes based on sorption on the surface of the "liquid-gas" interface of the products of the interaction of a surface-active substance (SAS) with ions of inorganic compounds occur. The method is suitable for the extraction of substances, including rare, trace and rare-earth metals from solutions with a very low concentration of components up to $10^{-8} \mathrm{~mol} / \mathrm{l}$. The ion flotation method has a high process rate and selectivity.

\section{Research methods}

To study the content of components in ash and slag waste, we used IR spectroscopic analysis and inductively coupled plasma optical emission spectrometry using iCAP 6500 DUO spectrometer.

IR spectroscopic analysis was performed using Agilent Cary 630 FTIR spectrometer in the range $4000-650 \mathrm{~cm}^{-1}$.

For concentrating rare-earth metal compounds, the main purpose is to separate aluminum, silicon and iron compounds, the content of which in coal ash and slag is very high.

After processing $1 \mathrm{~kg}$ of "G" brand ash of the Kotinskaya mine and "D" brand ash of the Kamyshinsky open pit, taken from Kemerovo state district power station, with $2.5 \mathrm{M}$ nitric acid, a gel of orthosilicic acid and silicates formed for one day. As a result of repeated washing and filtering the resulting mixture through a "white tape" filter, an extract was obtained for further processing.

The extract was neutralized with a $12 \%$ ammonia solution to $\mathrm{pH} 5$, and a large amount of a brown $\mathrm{Fe}(\mathrm{OH})_{3}$ precipitated. During the process, it is necessary not to exceed the $\mathrm{pH}$ level above the specified value, because co-precipitation of REE hydroxides is possible. After filtering the precipitate, the $\mathrm{pH}$ of the extract was adjusted to 8.5 with an ammonia solution for co-precipitation of rare earth hydroxides and aluminum.

In the course of further processing, the obtained hydroxides were re-dissolved in $0.5 \mathrm{~N}$ nitric acid and re-precipitation of rare earth metal oxalates with oxalic acid was carried out at $\mathrm{pH} 1$. With an increase in the $\mathrm{pH}$ of the solution to 8 , complete precipitation occurs, but alkaline earth metal oxalates and partially hydroxides of elements precipitate.

The resulting substances were dried in air and analyzed by IR spectroscopic method.

In addition to chemical methods of concentrating valuable components in ash and slag waste, ion-selective flotation is effective. Experiments were conducted in which sodium tetradecyl sulfate and sodium dodecyl sulfate were used as collectors and surfactant reagents, and the iso-octyl alcohol acted as the organic phase.

Flotation was carried out at a $\mathrm{pH}$ of 7.5-8.5; a ratio of organic and aqueous phases being from 1:20 to 1:60. As a result of the reaction, REEs are transported through the aqueous phase into the organic phase in the form of stable complex compounds. 
The analysis of the collected foam products was carried out by the inductively coupled plasma optical emission spectrometry in several stages.

A sample of $0.1 \mathrm{~g}$ ash was selected by quartering. The polyvinyl alcohol binder was weighed as much. Both samples (quantitatively transferred) were jointly rubbed in an agate mortar to aquire a constant shade of color. Then, the resulting mixture was poured into a mold in which, under a pressure of 5 tons $/ \mathrm{cm}^{2}$, it was pressed into a compact sample (pellet). The obtained compacts were produced according the same procedure as standard samples for spectrometer calibration.

The ash was dried to constant weight, then placed in a volumetric tube, poured with aqua regia up to graduation line of $50 \mathrm{ml}$. The resulting heterogeneous mixtures in hermetically sealed tubes were kept in a Hotblock special system of acid decomposition of samples. The extraction was carried out for 8 hours at $95^{\circ} \mathrm{C}$. The pressure was increased in closed vessels. Then the vessels cooled to room temperature until the morning of the next working day. Then the extract was separated from the precipitate quantitatively, as far as possible. Then the extract was diluted to the desired volume (according to the regulated concentration of background components). The resulting solution was analyzed.

The resulting pellets were placed in an UP 266 MACRO laser sampling chamber, purged with argon, which were sent to the spectrometer atomization torch. The solid-gas aerosol enters the atomization source, and the "liquid-gas" aerosol by means of a concentric nebulizer, a nebulizer chamber and a peristaltic pump.

\section{General results}

The position of the intense stretching vibration bands in the IR spectrum of 1617 and 1321 $\mathrm{cm}^{-1}$ characterizes the $\mathrm{C}-\mathrm{O}$ bond of carbonyl groups, which proves the presence of a large amount of metal oxalates in the sample.

In the area of $3437-3197 \mathrm{~cm}^{-1}$, wide fuzzy bands are observed related to stretching vibrations of associated hydroxides. Bands $919,724,786 \mathrm{~cm}^{-1}$ characterize the deformation vibrations of $\mathrm{OH}$ groups.

The content of the basic mineral components in the ash of the Kemerovo state district power station, determined by the method of optical emission spectrometry, is shown in table 1 .

Table 1. The content of rare, trace and rare-earth elements in the ash of Kemerovo state district power station.

\begin{tabular}{|c|c|c|}
\hline \multirow{2}{*}{ Elements } & \multicolumn{2}{|c|}{ Content } \\
\cline { 2 - 3 } & $\mathbf{\%}$ & $\mathbf{g} / \mathbf{t}$ \\
\hline $\mathrm{Sr}$ & $1.3 \cdot 10^{-2}$ & 130.00 \\
\hline $\mathrm{Ga}$ & $9.2 \cdot 10^{-4}$ & 9.20 \\
\hline $\mathrm{Zr}$ & $2.5 \cdot 10^{-4}$ & 2.50 \\
\hline $\mathrm{Nb}$ & $7.1 \cdot 10^{-4}$ & 7.10 \\
\hline $\mathrm{Mo}$ & $8.9 \cdot 10^{-4}$ & 8.90 \\
\hline $\mathrm{Au}$ & $1.2 \cdot 10^{-4}$ & 1.20 \\
\hline $\mathrm{V}$ & $5.5 \cdot 10^{-3}$ & 55.00 \\
\hline $\mathrm{REE}:$ & & \\
$\mathrm{Y}$ & $1.6 \cdot 10^{-3}$ & 16.00 \\
\hline $\mathrm{Eu}$ & $6.7 \cdot 10^{-5}$ & 0.67 \\
\hline $\mathrm{La}$ & $2.1 \cdot 10^{-3}$ & 21.00 \\
\hline $\mathrm{Pr}$ & $7.2 \cdot 10^{-4}$ & 7.20 \\
\hline $\mathrm{Sm}$ & $1.7 \cdot 10^{-4}$ & 17.00 \\
\hline
\end{tabular}


As a result of the process of flotoextraction in solution, metal cations form strong complexes with sodium tetradecyl sulfate, which, due to hydrophobicity, are converted into the organic phase - isooctyl alcohol (2-ethylhexanol).

2 litres of water, $33 \mathrm{ml}$ of 2-ethylhexanol (the ratio of organic to aqueous phases was $1: 60)$ and $27.11 \mathrm{~g}$ of tetradecyl sulfate were added to $500 \mathrm{~g}$ of ash. The process was carried out by means of a FL-240 flotation machine for 5, 10, 15 minutes. The result is stable gray foam with ash particles on the surface of the liquid.

At the same ratios of the initial components, but with the addition of $100 \mathrm{ml}$ of 2ethylhexanol, almost no foam forms after flotation, but a white mass is obtained on the surface of the liquid. The collected mass did not dry in air at room temperature.

Flotation was carried out in 2 stages with a ratio of initial components of $501.318 \mathrm{~g}$ of ash to 2 litres of water with the addition of $33 \mathrm{ml}$ of 2-ethylhexanol and $30.34 \mathrm{~g}$ of tetradecyl sulfate. After the first flotation, a gray film was formed with the extracted particles of ash components, and at the second stage the film was not formed. As a result, we can conclude that tetradecyl sulfate is rather highly efficient as a collector reagent.

During flotation of ash residues (179.923 g) with two liters of water, $33 \mathrm{ml}$ of isooctyl alcohol and $26.846 \mathrm{~g}$ of tetradecyl sulfate foam was obtained, but very few particles were recovered due to the small amount of ash.

Experiments were conducted using sodium dodecyl sulfate as a surfactant, combining the properties of an ion-type collector blowing agent and a frothing agent.

2 litres of water and $52 \mathrm{ml}$ of 2-ethylhexanol (ratio of aqueous to organic phases 1:40) and $2.00 \mathrm{~g}$ of sodium dodecyl sulfate were added to $500 \mathrm{~g}$ of ash. When the flotation process was carried out for 5 and 10 minutes, a small amount of foam was obtained, but when the suspension was left to stand undisturbed, stable foam products formed, which were dried in air and calcinated at a temperature of $1000{ }^{\circ} \mathrm{C}$ for two hours.

The results of studies of the obtained substances are presented in Table 2.

Table 2. The content of rare, trace and rare-earth elements in concentrates.

\begin{tabular}{|c|c|}
\hline Title & Content in the concentrate, $\% / \mathbf{g} / \mathbf{t}$ \\
\hline $\mathrm{Sr}$ & $1.3 \cdot 10^{-1} / 1300$ \\
\hline $\mathrm{Ga}$ & $4.9 \cdot 10^{-3} / 49$ \\
\hline $\mathrm{Zr}$ & $1.6 \cdot 10^{-1} / 1600$ \\
\hline $\mathrm{Nb}$ & $8.7 \cdot 10^{-3} / 87$ \\
\hline $\mathrm{V}$ & $3.2 \cdot 10^{-1} / 3200$ \\
\hline $\mathrm{Mo}$ & $2.2 \cdot 10^{-2} / 220$ \\
\hline$\Sigma \mathrm{P} 33$ & $7.9 \cdot 10^{-2} / 790$ \\
\hline
\end{tabular}

\section{Conclusions}

As a result of the studies, it can be concluded that the nitric acid leaching method with the separation of iron (III) hydroxide and the subsequent precipitation of rare-earth metals in the form of oxalates or hydrates is quite advantageous from an economic point of view, because does not require expensive equipment and reagents. On the other hand, it is more efficient to use it at higher contents of rare-earth components in the samples.

To treat and concentrate valuable metals in depleted ash and slag raw materials, it is promising to use flotation extraction before chemical methods [16-18].

The analysis showed that the highest concentration of REE in foam products is formed when sodium dodecyl sulfate is used as a collector and a frothing agent, because it is consumed in smaller amounts during extraction and is a selective reagent for the formation of complexes with lanthanides. 


\section{References}

1. O. S. Danilov, A. V. Belov, I. V. Grebenyuk, Mining Informational and Analytical Bulletin, 7, 16 (2018)

2. P. Deutz, H. Baxter, D. Gibbs, W. M. Mayers, H. I. Gomes, Geoforum, 85, 336 (2017)

3. D. Bradio, W. Zukowski, P. Czupryński, K. Witkowski, Inzynieria Mineralna, 16 (1), 163 (2015)

4. Z. Ma, S. Zhang, H. Zhang, F. Cheng, J. of Cleaner Production, 230, 302 (2019)

5. W. Urbańczyk, M. Lutyński, IOP Conference Series: Materials Science and Engeneering, 641 (1), 155425 (2019)

6. A. Kumari, R. Parween, S. Chakravarty, K. Parmar, D.D. Pathak, J.-C. Lee, M.K. Jha, Hydrometallurgy, 187, 1 (2019)

7. V. Balaram, Geoscience Frontiers, 10(4), 1285 (2019)

8. P. Liu, R. Huang, Y. Tang, Environmental Science and Technology, 53(9), 5369 (2019)

9. Z. Wang, S. Dai, J. Zou, D. French, I.T. Graham, International J. of Coal Geology, 203, 1 (2019)

10. M. Tang, C. Zhou, N. Zhang, J. Pan, S, Cao, T. Hu, W. Ji, Z. Wen, T. Nie, International J. of Coal Preparation and Utilization, (to be published)

11. C. Lanzerstorfer, Energy Reports, 4, 660 (2018)

12. S. Das, G. Gaustad, A. Sekar, E. Williams J. of Cleaner Production, 189, 539 (2018)

13. P. K. Sahoo, K. Kim, M. A. Powell, S. M. Equeenuddin. International J. of Coal Science and Technology, 3(3), 267 (2016)

14. R. K. Taggart, J. C. Hower, G. S. Dwyer, H. Hsu-Kim, Environmental Science and Technology, 50(11), 5919 (2016)

15. V. I. Kuz'min, V. N, Kuz'mina, P. N. Kuznetsov, S. M. Kolesnikova, Solid Fuel Chemistry, 50(2), 120 (2016)

16. B. S. Ksenofontov, A. S. Kozodaev, R. A. Taranov, Ecology and Industry of Russia, 20 (4), 12 (2016)

17. R. C. Smith, R. K. Taggart, J. C. Hower, M. R. Wiesner, H. Hsu-Kim, Environmental Science and Technology, 53(8), 4490 (2019)

18. L. Chang, Y. Cao, G. Fan, C. Li, W. Peng, RSC Advances, 9 (35), 20226 (2019) 